\section{Competences in Cardiopulmonary Resuscitation Matters in Pregnancy}

\section{Ana Álvarez Bartolomé*, Amelia Sanz Lorenzana, Ana Díaz Herrero, Cristina Robledo Juarez, Juan Alfonso Valenciano Rodriguez and Oscar Martínez-Pérez}

Hospital Universitario Puerta de Hierro Majadahonda, Madrid, Spain

\begin{abstract}
Objective: To analyse the level of knowledge of out-of-hospital emergency care personnel on the management of Cardiac Arrest (CA) in pregnant women, to determine whether there are deficiencies in training and to assess the creation of a course on cardiopulmonary resuscitation in pregnant women for non-obstetric personnel.

Materials and methods: We analysed the results of five questions addressing the management of CA in pregnant women from a questionnaire conducted prior to the Out-of-Hospital Obstetric Emergencies course to determine the level of knowledge of doctors and nurses regarding out-of-hospital emergencies in the management of CA in pregnant women.

Results: After analysing four questions related to the management of CA in pregnant women, the mean proportion of correct answers was $54.48 \%$; only $21.79 \%$ of participants answered all questions correctly, and $14.4 \%$ did not answer any questions correctly. Regarding professionals' perceptions about their abilities to perform CPR in a pregnant woman, $67.12 \%$ of students did not think they were sufficiently trained to perform resuscitation in a pregnant woman, and $79.3 \%$ did not know how to perform a perimortem caesarean section.

Conclusion: There are deficiencies in the knowledge about the management of resuscitation in a pregnant woman; moreover, outof-hospital emergency care personnel perceived a lack of training on this subject. Therefore, an Advanced Cardiac Life Support in Pregnancy course must be created for staff who do not work in a delivery room, since these training needs are not covered in Advanced Cardiac Life Support in Adults courses.
\end{abstract}

*Corresponding author: Ana Álvarez Bartolomé, Hospital Universitario Puerta de Hierro Majadahonda, Av. Los Robles 2, Portal 6 1A, 28250, Torrelodones, Madrid, Spain, E-mail: anaalvarezbartolome@gmail.com

Citation: Bartolomé AA, Lorenzana AS, Herrero AD, Juarez CR, Rodriguez JAV et al. (2020) Competences in Cardiopulmonary Resuscitation Matters in Pregnancy. J Reprod Med Gynecol Obstet 5: 065.

Received: December 02, 2020; Accepted: December 24, 2020; Published: December 30, 2020

Copyright: @ 2020 Bartolomé AA, et al. This is an open-access article distributed under the terms of the Creative Commons Attribution License, which permits unrestricted use, distribution, and reproduction in any medium, provided the original author and source are credited.
Keywords: Advance cardiac life support; Caesarean section; Cardiac arrest; Cardiopulmonary resuscitation; Pregnancy

\section{Introduction}

Cardiac Arrest (CA) that occurs during pregnancy is assumed to be a tragedy and is a challenge for the teams that attend to these patients. This emergency tests the knowledge and skills of the medical personnel because two lives depend on the immediacy, organization and ability of the resuscitation team. CA during pregnancy has catastrophic consequences if there is no correct action. Fortunately, the probability that a pregnant patient suffers from CA is very small, since pregnant women are usually young and healthy (incidence of in-hospital Maternal Cardiac Arrest (MCA) varies from 1:20,000$1: 12,000$ pregnancies); $[1,2]$ at the out-of-hospital level in Canada, the incidence is $1.71: 100,000$ pregnancies) [1]. However, MCA and maternal mortality are frequently underestimated and underreported in $22-67 \%$ of cases, $[3,4]$ particularly at the out-of-hospital level if there are no witnesses to indicate that the woman is pregnant [5].

Given the physiological changes that occur in pregnancy, the sequence of Cardiopulmonary Resuscitation (CPR) that is taught in a generalized manner when the victim is an adult must be adapted for pregnant women experiencing CA [6]. Both the International Liaison Committee on Resuscitation (ILCOR) and American Heart Association (AHA) 2015 guidelines recommend lateral uterine displacement for quality compressions and performing a perimortem caesarean section in pregnant women with a fundal height above the umbilicus (20-22 weeks of gestation, due to aortocaval compression syndrome) if spontaneous circulation is not achieved after 4 minutes of resuscitation manoeuvres [6-8].

In 1986, Katz defined "perimortem caesarean section as delivery or birth by caesarean section after the initiation of maternal CPR manoeuvres" [9]. Perimortem caesarean section is a resuscitative surgical technique of short duration and with few material requirements (there is no need to prepare the incision site) to improve the chances of survival of pregnant women past 20 gestational weeks, regardless of the foetal condition [10]. This technique has shown a clear maternal benefit in up to $1 / 3$ of the series, and in no cases has it indicated a harmful effect $[4,11]$. In cases in which there is an irreversible cause of arrest and in which CPR manoeuvres are futile, there is no reason to delay this procedure when the foetus can be viable and its sole purpose is to save the foetus [11]. Caesarean section is a technique that can be performed by non-obstetric medical personnel with basic training [12].

The principles supported by international guidelines hold that resuscitative hysterotomy should be performed after 4 to 5 minutes of stopping the CA if there is no Return of Spontaneous Circulation (ROSC) [7,8] because irreversible brain damage as a consequence of hypoxia begins to occur 4-6 minutes after the cessation of blood flow [11]. Health personnel may be reluctant to perform a perimortem caesarean section if it has been much longer since the start of CA 
Citation: Bartolomé AA, Lorenzana AS, Herrero AD, Juarez CR, Rodriguez JAV, et al. (2020) Competences in Cardiopulmonary Resuscitation Matters in Pregnancy. J Reprod Med Gynecol Obstet 5: 065.

due to fear of poor neurological results [13]. The survival curves for women and neonates have shown lesion-free survival rates of $50 \%$ with perimortem caesarean delivery up to 25 minutes after MCA, so even if the caesarean does not occur within 4 to 5 minutes, there are still benefits, and resuscitative hysterotomy should be considered [14]. This is very important in out-of-hospital care, in which most arrests are not witnessed and the arrival of the advanced resuscitation team occurs more than 5 minutes after the start of CA, so eliminating the 4 to 5 -minute range and advocating for foetal removal as quickly as possible has been proposed for maternal and foetal survival [14]

The AHA guidelines for arrest during pregnancy distinguish between out-of-hospital care protocols for pregnant women in CA in which perimortem caesarean section is not supported (because paramedics who attend emergencies are not authorized to perform it) and hospital protocols where there are physicians who can perform this procedure [8]. The survival of pregnant women who suffer outof-hospital CA is lower than that in women who suffer in-hospital CA (16.6\% vs. 50\%) [1]. The difference lies in the aetiology and the level of monitoring and access to treatments, such as perimortem caesarean section. The results can be improved if out-of-hospital emergency services can perform a perimortem caesarean section followed by a quick transfer to the hospital [15].

In our country, unlike other prehospital care systems, there are doctors and nurses in advanced cardiac life support units who are accredited to perform resuscitative surgical manoeuvres such as perimortem caesarean section. However, there is no specific programme for training in this type of emergency in the out-ofhospital setting, and before designing this training, we investigated the knowledge and attitudes of active professionals in an organization specialized in out-of-hospital care regarding CPR in pregnant women. The Multiprofessional Simulation Team (MST) is a working group composed of doctors, nurses and midwives from the Obstetrics and Gynaecology Service and doctors from the Anaesthesia and Resuscitation Service of the Puerta de Hierro Majadahonda University Hospital (Hospital Universitario Puerta de Hierro Majadahonda HUPHM). We used clinical simulation as an educational technique for the management of obstetric emergencies at both the in-hospital and out-of-hospital levels, in collaboration with SUMMA 112 medical emergencies service. As a result of this collaboration, a working group emerged in September 2016 that included doctors, nurses and technicians. Both the MST and SUMMA 112 collaborated to develop an Advanced Cardiac Life Support programme in pregnant women for out-of-hospital and hospital emergency personnel when there is no obstetric team on call. To create this course, the results of the questions about CPR in pregnant women in the questionnaires from the Out-of-Hospital Obstetric Emergencies course were used to determine whether it was necessary to create this course due to the presence of knowledge gaps and the lack of training reported by these personnel.

The purpose of this article is to present the results of the analysis of the questions mentioned above and to understand the deficits in knowledge and skills of out-of-hospital emergency personnel in Advanced Cardiac Life Support in Pregnancy (ACLS-P). This article is the result of research that has concluded with a new programme of life support in pregnant women of the National CPR Plan of the Sociedad Española de Medicina Intensiva y Unidades Coronarias (Spanish Society of Intensive Care Medicine and Coronary Units).

\section{Methods}

The MST performed four accredited mixed courses (face-to-face and non-face-to-face) with the continuing training commission for Childbirth Assistance and Out-of-Hospital Obstetric Emergencies funded by SUMMA 112. This is an 8-hour course for out-of-hospital care doctors and nurses that is composed of theoretical classes on normal delivery assistance, breech delivery, obstetric haemorrhage, eclampsia, severe preeclampsia, cord prolapse and concepts of cardiopulmonary resuscitation in pregnant women; additionally, workshops with simulators of normal delivery, breech, haemorrhage, cord prolapse and eclampsia are included, but there are no workshops on CPR in pregnant women.

As part of the accredited programme of the course and to determine the participants' previous knowledge, the students were sent an anonymous electronic survey (Figure 1) with 17 questions about these emergencies (four questions addressed CA in pregnant women, and a fifth question addressed the determination of gestational age, which was introduced in the last two editions, so only 128 students answered this question) in addition to seven questions about previous training and attitudes about ACLS-P. This questionnaire was not mandatory to obtain credits, so it was completed voluntarily and anonymously.

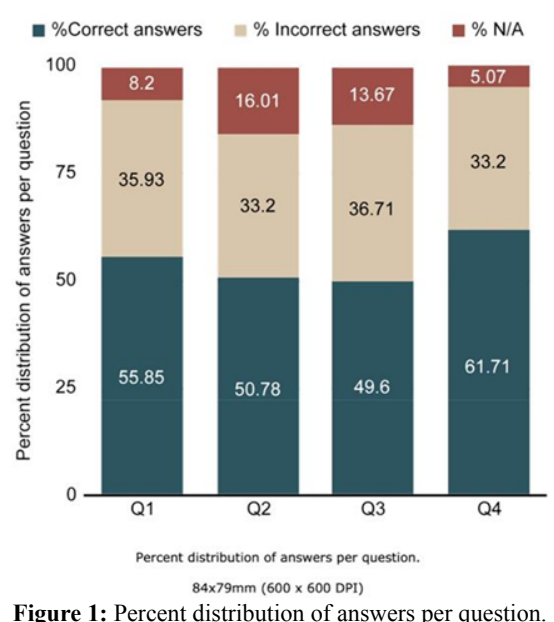

Using the programme Stata version 15.1, a descriptive analysis of each of the answers to the five theoretical questions was performed both to determine whether they were correct and to assess the most common failures to influence their correction during the content of the ACLS-P course. We compared whether there were differences in correct and incorrect answers depending on whether the staff had received prior training in CPR on pregnant women. We also assessed whether they believe that they are sufficiently trained and whether they would be confident enough to perform a perimortem caesarean section to determine whether there was a perception of a lack of training and therefore a need for such training.

\section{Results}

The four editions of this course were held in November 2016, May and November 2017 and November 2018 with a total of 256 students (108 doctors and 148 nurses). Only 223 students answered the questions on prior training and attitudes towards perimortem 
Citation: Bartolomé AA, Lorenzana AS, Herrero AD, Juarez CR, Rodriguez JAV, et al. (2020) Competences in Cardiopulmonary Resuscitation Matters in Pregnancy. J Reprod Med Gynecol Obstet 5: 065.

caesarean because these questions were not included enough in advance in one of the analysed editions. The 256 students answered an average of $54.48 \%$ of the first four theoretical questions on CA in pregnant women correctly; only $21.79 \%$ answered all questions correctly, and $14.4 \%$ did not answer any correctly (Table 1). The distributions of correct, incorrect and "not applicable" answers based on each of the four questions were quite similar, as shown in figure 1 , and the percentage of responses to each of the options according to question are shown in figure 2. A total of 128 students answered the fifth question on determining gestational age, with $40.62 \%$ answering correctly, which was lower than the correct response rate to the previous questions. Additionally, 31.25\% answered incorrectly and $28.12 \%$ answered "not applicable".

\begin{tabular}{|c|c|c|}
\hline Correct answers & Frequency & Percentage \\
\hline 0 & 37 & 14.4 \\
\hline 1 & 55 & 21.4 \\
\hline 2 & 48 & 18.68 \\
\hline 3 & 60 & 23.74 \\
\hline 4 & 56 & 21.79 \\
\hline Total & 256 & 100 \\
\hline
\end{tabular}

Table 1: No of students and $\%$ that answer correctly 1, 2, 3 or all 4 questions.

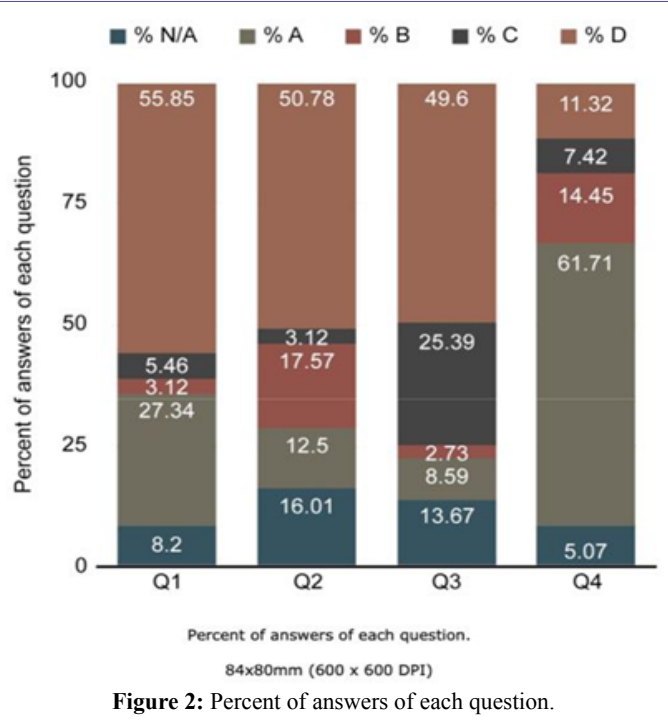

A total of 223 students answered the seven questions on prior training and attitudes towards perimortem caesarean section; 33 did not provide answers. A total of $215 \mathrm{had}$ completed a previous advanced cardiac life support course (up to 94 students over five courses), and up to 88 had previous ACLS training in pregnant women. Previous training in ACLS in pregnant women was not statistically significantly associated with better results in the four questions on CPR in pregnant women. In the assessment of professionals' perceptions about their abilities to perform CPR on a pregnant woman, few felt fully trained. A total of $67.12 \%$ of the students thought that they were not sufficiently trained to perform resuscitation on a pregnant woman, and $79.3 \%$ thought that they would not know how to perform a perimortem caesarean section. Additionally, $8.56 \%$ thought that they may only be prepared for CPR in pregnant women, and $11.6 \%$ thought that they would be able to perform a resuscitative hysterectomy. Although only $8.97 \%$ of the students knew how to perform a caesarean section and $47.30 \%$ knew how to determine the gestational age, $43.19 \%$ of the students would be confident to perform it if necessary.

\section{Discussion}

The recommendations for the management of $\mathrm{CA}$ in pregnant women are based on expert recommendations, clinical cases and the extrapolation of data from non-pregnant patients. However, for resuscitation manoeuvres to be useful, it is imperative to understand the physiological changes in pregnancy to perform the appropriate actions [16]. Additionally, the personnel who may address these situations must be well prepared. This study reveals a lack of doctors' and nurses' knowledge during out-of-hospital emergencies; the average correct response rate was $54.84 \%$, and there was a lack of teaching of resuscitation in pregnant women, as up to $60.81 \%$ of participants had not received any CPR training for pregnant women.

Our results are similar to those of Einav and Cohen (the two most referenced studies in terms of theoretical knowledge in maternal CA), with a success rate lower than $85 \%$, which must be achieved to pass the Advanced Cardiac Life Support course [17,18]. Our results are also consistent with studies of simulated CA scenarios in pregnant women by Lipman and Berkenstadt, in which a poor level of technical skills was demonstrated $[19,20]$. In addition to the low success rate, the most common error in each of the questions is also an important point to consider. A total of $27.34 \%$ of students thought that lateralization of the uterus to the left is recommended but not required in pregnancies of more than 30 weeks, and $12.5 \%$ thought that the lateralization should be performed to the right, which is important not only in resuscitation manoeuvres but also in the care of the pregnant patient in a critical situation. The guidelines indicate that it is very important to never interrupt the compressions, since this measure has been shown to increase survival; however, $17.57 \%$ of the students answered that the compressions should be stopped while performing the perimortem caesarean section. In addition, in terms of the time in which the caesarean section should be started, $25.39 \%$ responded that it should start 6 minutes after CA occurs, but it should be kept in mind that after that time, brain damage begins to occur due to anoxia. Finally, caesarean section should be performed in the place where CA occurs, although $11.32 \%$ would transfer the patient; however, transferring the patient both in clinical cases and in simulation scenarios entails delays in performing the caesarean section [3] and a worsening of the quality of resuscitation manoeuvres. The four previously mentioned studies on the knowledge of ACLS in pregnant women were conducted at the in-hospital level. No studies had previously been performed in the out-of-hospital setting, as our study was. Two recent studies conducted in France and Canada measured the incidence, results and follow-up of the guidelines in the care of MCA at the out-of-hospital level $[1,5]$. In Canada, six cases of MCA were recorded, of which only one mother and two newborns survived to hospital discharge, although three mothers did present ROSC (two of them before arriving at the hospital); maternal survival at hospital discharge was $16.6 \%$, lower than the $59 \%$ recorded in cases of in-hospital MCA. In all cases, the recording of the quality of the compressions was good, and the route was channelled at the supradiaphragmatic level, but in no case was the uterus manually moved to the left during the transfer, and only in one case was the patient lateralized (measure not currently recommended if sufficient resources are available because the quality 
Citation: Bartolomé AA, Lorenzana AS, Herrero AD, Juarez CR, Rodriguez JAV, et al. (2020) Competences in Cardiopulmonary Resuscitation Matters in Pregnancy. J Reprod Med Gynecol Obstet 5: 065.

of compressions decreases) [1]. In France, 16 cases of CA in pregnant women were recorded, of which 10 occurred over 20 gestational weeks; only two women survived to hospital discharge (none were pregnant for more than 20 weeks), no team lateralized the uterus, [5] and the average transfer time to the hospital was 94 minutes. The lack of uterine lateralization may be due to lack of knowledge, the fact that they did not know the patient was over 20 gestational weeks or that the manoeuvre was not recorded. In both cases, out-of-hospital emergency teams are not trained on how to perform perimortem caesarean section. In Canada, six perimortem caesarean sections were performed on arrival at the hospital, but none were performed in less than 5 minutes after arrival at the emergency room; in France, they were only performed in three cases before arrival at the hospital.

The purpose of perimortem caesarean section is to improve the chances of survival of the mother, which should be the objective at all times [10]. However, in most cases, resuscitation manoeuvres will be futile due to the cause of maternal CA. In these cases, perimortem caesarean section should not be delayed and should be performed to save the foetus if the pregnancy is more than 24 weeks of gestation [11]. Out-of-hospital emergency teams should be more aware of the importance of recognizing gestational age and the benefits of perimortem caesarean section as soon as possible [15]. In 2016, the MOET emphasized that all medical professionals with the necessary skills can perform a perimortem caesarean section and should not be criticized for it [15]. Moreover, doctors in hospitals and out-of-hospital emergencies should have the knowledge to perform perimortem caesarean section without an obstetrician present, followed by temporary packing with compresses and clamps for later closure by a specialist [10].

In Spain, out-of-hospital emergency teams of mobile ICUs are composed of at least one doctor, a nurse and a technician. Spanish laws protect the performance of a perimortem caesarean section in the context of resuscitative measures for any professional licensed in medicine and surgery [21]. Although $61.71 \%$ of students know that a perimortem caesarean section increases the chances of rescuing a pregnant patient from CA, only $49.6 \%$ know that it should be performed 4 minutes after the start of CA. Furthermore, $8.97 \%$ affirmed that they knew how to perform a perimortem caesarean section, and $11.6 \%$ said that they may know (Figure 3), although only $43.19 \%$ were confident enough to do it (Figure 4).

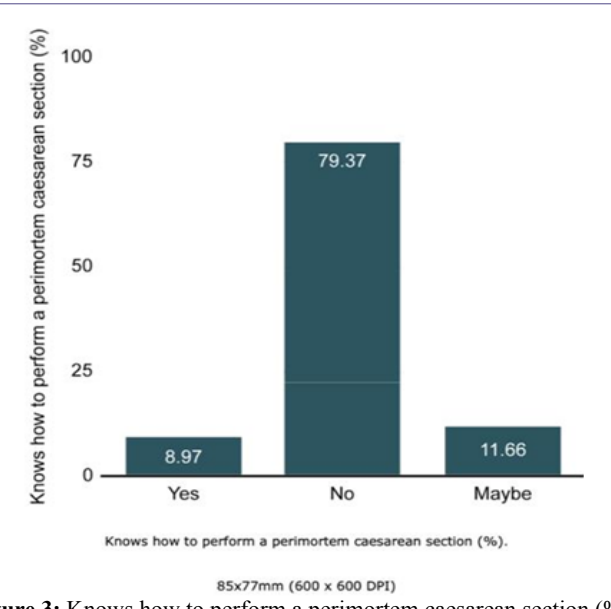

Figure 3: Knows how to perform a perimortem caesarean section (\%).

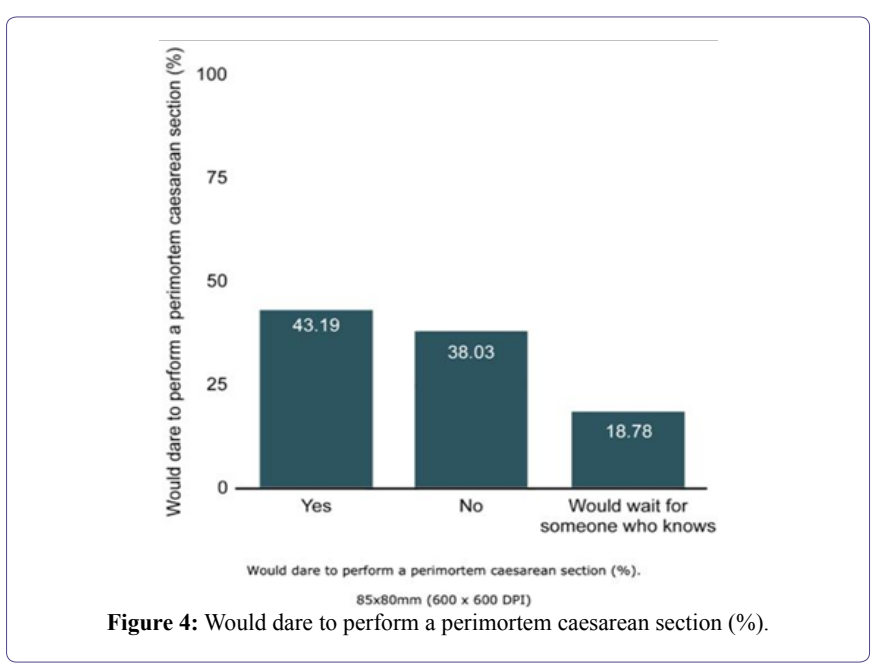

This is the first study to date that has investigated this situation in our country in a large sample of active professionals. We believe that these results obtained in Madrid can be extrapolated to the rest of the country. This study has some limitations. There were only five theoretical questions, although seven questions addressed their previous training and their knowledge (highlighting the lack of training on CPR in pregnant women, perimortem caesarean section and determination of gestational age). Additionally, many questions were not answered by a high proportion of students, likely due to a lack of knowledge. We also do not know how long it has been since the students completed their last CPR course. An advantage of this study is that it is the first study available on the knowledge of the modifications of CPR in pregnant women in staff working in out-ofhospital emergencies, in addition to containing a large sample of 253 students.

The staff working at the out-of-hospital level has limited knowledge on maternal CPR, possibly because of the lack of training on obstetric patients in the ACLS courses. Training through simulation in obstetric emergencies and CPR has been shown to improve results, so we believe that it is necessary to implement specific courses on ACLS in pregnant women and complete the Advanced Cardiac Life Support in Pregnancy course, currently adopted by the National CPR Plan, whose methodology and results will be the subject of another article.

\section{Availability of Data and Materials}

The datasets used and/or analysed during the current study are available from the corresponding author on reasonable request.

\section{Competing Interests}

The authors declare that they have no competing interests.

\section{Authors' Contribution}

Ana Álvarez: Conception and design of work, acquisition and interpretation of data, writing.

Amelia Sanz: Conception, acquisition of data.

Ana Diez Herrero: Conception and designing of work.

Cristina Herrero: Acquisition of data.

Juan Valenciano: Conception and designing of work. 
Citation: Bartolomé AA, Lorenzana AS, Herrero AD, Juarez CR, Rodriguez JAV, et al. (2020) Competences in Cardiopulmonary Resuscitation Matters in Pregnancy. J Reprod Med Gynecol Obstet 5: 065.

Oscar Martínez: Conception and design of work, writing and revised it.

\section{Acknowledgement}

Authors declare this article has not received any public or private funding.

\section{References}

1. Lipowicz AA, Cheskes S, Gray SH, Jeejeebhoy F, Lee J, et al. (2018) Incidence, outcomes and guideline compliance of out-of-hospital maternal cardiac arrest resuscitations: A population-based cohort study. Resuscitation 132: $127-132$.

2. Zelop CM, Einav S, Mhyre JM, Lipman SS, Arafeh J, et al. (2018) Characteristics and outcomes of maternal cardiac arrest: A descriptive analysis of Get with the guidelines data. Resuscitation 132: 17-20.

3. Eldridge AJ, Ford R (2016) Perimortem caesarean deliveries. Int J Obstet Anesth 27: 46-54.

4. Einav S, Kaufman N, Sela HY (2012) Maternal cardiac arrest and perimortem caesarean delivery: Evidence or expert-based? Resuscitation 83: 1191-1200.

5. Maurin O, Lemoine S, Jost D, Lanoë V, Renard A, et al. (2019) Maternal out-of-hospital cardiac arrest: A retrospective observational study. Resuscitation 135: 205-211.

6. Jeejeebhoy FM, Zelop CM, Lipman S, Carvalho B, Joglar J, et al. (2015) Cardiac Arrest in Pregnancy: A Scientific Statement From the American Heart Association. Circulation 132: 1747-1773.

7. Monsieurs KG, Nolan JP, Bossaert LL, Greif R, Maconochie IK, et al. (2015) European Resuscitation Council Guidelines for Resuscitation 2015: Section 1. Executive summary. Resuscitation 95: 1-80.

8. Neumar RW, Shuster M, Callaway CW, Gent LM, Atkins DL, et al. (2015) Part 1: Executive Summary: 2015 American Heart Association Guidelines Update for Cardiopulmonary Resuscitation and Emergency Cardiovascular Care. Circulation 132: 315-367.

9. Katz VL, Dotters DJ, Droegemueller W (1986) Perimortem cesarean delivery. Obstet Gynecol 68: 571-576.
10. Parry R, Asmussen T, Smith JE (2016) Perimortem caesarean section. Emerg Med J 33: 224-229.

11. Katz V, Balderston K, DeFreest M (2005) Perimortem cesarean delivery: were our assumptions correct? Am J Obstet Gynecol 192: 1916-1920.

12. Dijkman A, Huisman CM, Smit M, Schutte JM, Zwart JJ, et al. (2010) Cardiac arrest in pregnancy: Increasing use of perimortem caesarean section due to emergency skills training? BJOG 117: 282-287.

13. Fadel HE (2011) Postmortem and perimortem cesarean section: historical, religious and ethical considerations. J IMA 43: 194-200.

14. Benson MD, Padovano A, Bourjeily G, Zhou Y (2016) Maternal collapse: Challenging the four-minute rule. EBioMedicine 6: 253-257.

15. Hillman SL, Cooper NC, Siassakos D (2019) Born to survive: A critical review of out-of-hospital maternal cardiac arrests and pre-hospital perimortem caesarean section. Resuscitation 135: 224-225.

16. Bennett TA, Katz VL, Zelop CM (2016) Cardiac Arrest and Resuscitation Unique to Pregnancy. Obstet Gynecol Clin North Am 43: 809-819.

17. Einav S, Matot I, Berkenstadt H, Bromiker R, Weiniger CF (2008) A survey of labour ward clinicians' knowledge of maternal cardiac arrest and resuscitation. Int J Obstet Anesth 17: 238-242.

18. Cohen SE, Andes LC, Carvalho B (2008) Assessment of knowledge regarding cardiopulmonary resuscitation of pregnant women. Int J Obstet Anesth 17: 20-25.

19. Lipman SS, Daniels KI, Carvalho B, Arafeh J, Harney K, et al. (2010) Deficits in the provision of cardiopulmonary resuscitation during simulated obstetric crises. Am J Obstet Gynecol 203: 179.

20. Berkenstadt H, Ben-Menachem E, Dach R, Ezri T, Ziv A, et al. (2012) Deficits in the provision of cardiopulmonary resuscitation during simulated obstetric crises: results from the Israeli Board of Anesthesiologists. Anesth Analg 115: 1122-1126.

21. López RL, Benjumea R (2018) Aspectos medico legales en RCP en gestante. In: Perez OM, Herrero AD, Lorenzana AS, Lopez AL, et al. (eds.). Soporte Vital Avanzado en Gestante. Aran, Madrid, Spain. 
Citation: Bartolomé AA, Lorenzana AS, Herrero AD, Juarez CR, Rodriguez JAV, et al. (2020) Competences in Cardiopulmonary Resuscitation Matters in Pregnancy. J Reprod Med Gynecol Obstet 5: 065.

\section{ANNEX 1.}

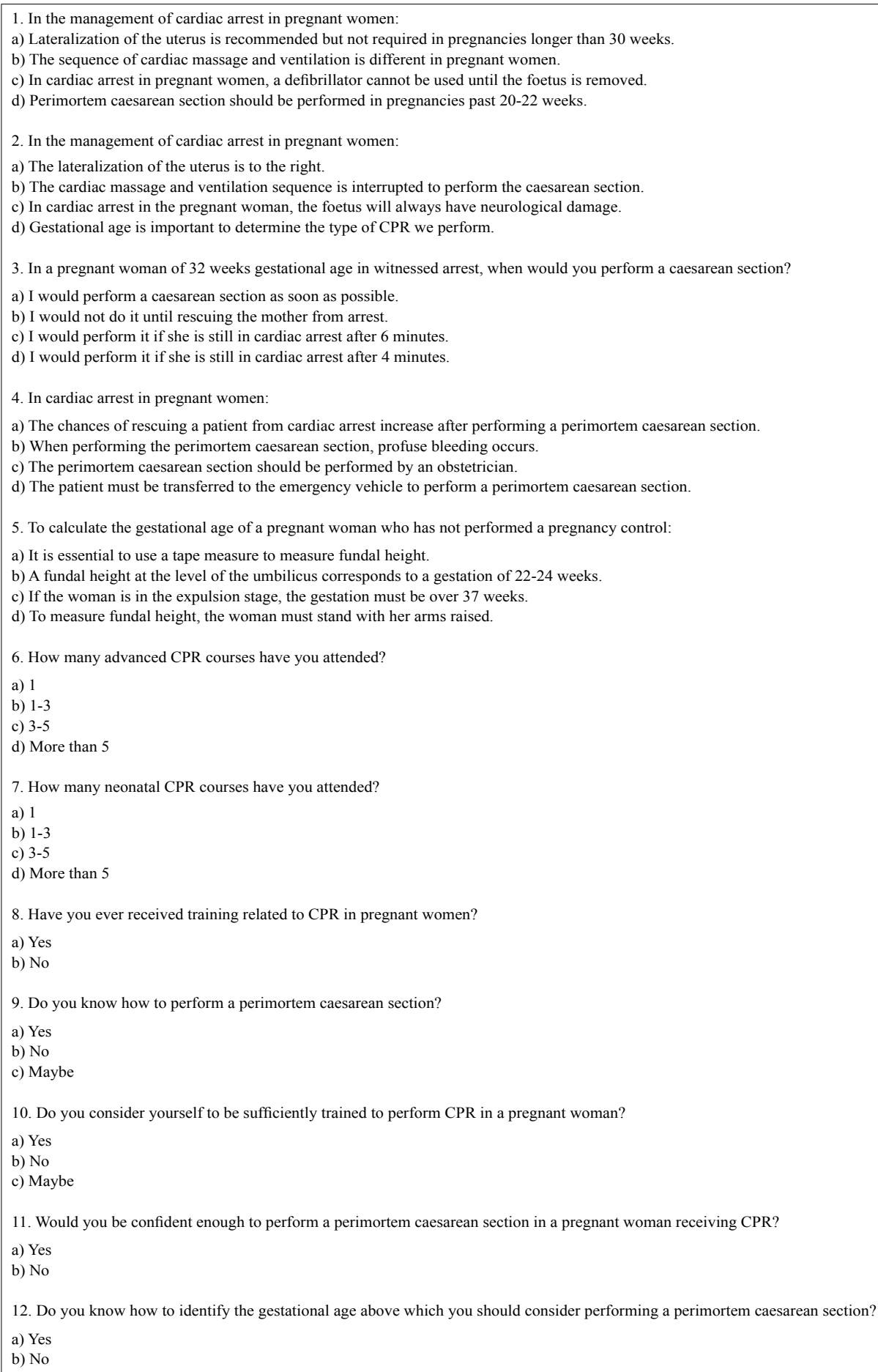




\section{di \\ Hetario}

Advances In Industrial Biotechnology | ISSN: 2639-5665

Advances In Microbiology Research | ISSN: 2689-694X

Archives Of Surgery And Surgical Education | ISSN: 2689-3126

Archives Of Urology

Archives Of Zoological Studies | ISSN: 2640-7779

Current Trends Medical And Biological Engineering

International Journal Of Case Reports And Therapeutic Studies | ISSN: 2689-310X

Journal Of Addiction \& Addictive Disorders | ISSN: 2578-7276

Journal Of Agronomy \& Agricultural Science | ISSN: 2689-8292

Journal Of AIDS Clinical Research \& STDs | ISSN: 2572-7370

Journal Of Alcoholism Drug Abuse \& Substance Dependence | ISSN: 2572-9594

Journal Of Allergy Disorders \& Therapy | ISSN: 2470-749X

Journal Of Alternative Complementary \& Integrative Medicine | ISSN: 2470-7562

Journal Of Alzheimers \& Neurodegenerative Diseases | ISSN: 2572-9608

Journal Of Anesthesia \& Clinical Care | ISSN: 2378-8879

Journal Of Angiology \& Vascular Surgery | ISSN: 2572-7397

Journal Of Animal Research \& Veterinary Science | ISSN: 2639-3751

Journal Of Aquaculture \& Fisheries | ISSN: 2576-5523

Journal Of Atmospheric \& Earth Sciences | ISSN: 2689-8780

Journal Of Biotech Research \& Biochemistry

Journal Of Brain \& Neuroscience Research

Journal Of Cancer Biology \& Treatment | ISSN: 2470-7546

Journal Of Cardiology Study \& Research | ISSN: 2640-768X

Journal Of Cell Biology \& Cell Metabolism | ISSN: 2381-1943

Journal Of Clinical Dermatology \& Therapy | ISSN: 2378-8771

Journal Of Clinical Immunology \& Immunotherapy | ISSN: 2378-8844

Journal Of Clinical Studies \& Medical Case Reports | ISSN: 2378-8801

Journal Of Community Medicine \& Public Health Care | ISSN: 2381-1978

Journal Of Cytology \& Tissue Biology | ISSN: 2378-9107

Journal Of Dairy Research \& Technology | ISSN: 2688-9315

Journal Of Dentistry Oral Health \& Cosmesis | ISSN: 2473-6783

Journal Of Diabetes \& Metabolic Disorders | ISSN: 2381-201X

Journal Of Emergency Medicine Trauma \& Surgical Care | ISSN: 2378-8798

Journal Of Environmental Science Current Research | ISSN: 2643-5020

Journal Of Food Science \& Nutrition | ISSN: 2470-1076

Journal Of Forensic Legal \& Investigative Sciences | ISSN: 2473-733X

Journal Of Gastroenterology \& Hepatology Research | ISSN: 2574-2566
Journal Of Genetics \& Genomic Sciences | ISSN: 2574-2485

Journal Of Gerontology \& Geriatric Medicine | ISSN: 2381-8662

Journal Of Hematology Blood Transfusion \& Disorders | ISSN: 2572-2999

Journal Of Hospice \& Palliative Medical Care

Journal Of Human Endocrinology | ISSN: 2572-9640

Journal Of Infectious \& Non Infectious Diseases | ISSN: 2381-8654

Journal Of Internal Medicine \& Primary Healthcare | ISSN: 2574-2493

Journal Of Light \& Laser Current Trends

Journal Of Medicine Study \& Research | ISSN: 2639-5657

Journal Of Modern Chemical Sciences

Journal Of Nanotechnology Nanomedicine \& Nanobiotechnology | ISSN: 2381-2044

Journal Of Neonatology \& Clinical Pediatrics | ISSN: 2378-878X

Journal Of Nephrology \& Renal Therapy | ISSN: 2473-7313

Journal Of Non Invasive Vascular Investigation | ISSN: 2572-7400

Journal Of Nuclear Medicine Radiology \& Radiation Therapy | ISSN: 2572-7419

Journal Of Obesity \& Weight Loss | ISSN: 2473-7372

Journal Of Ophthalmology \& Clinical Research | ISSN: 2378-8887

Journal Of Orthopedic Research \& Physiotherapy | ISSN: 2381-2052

Journal Of Otolaryngology Head \& Neck Surgery | ISSN: 2573-010X

Journal Of Pathology Clinical \& Medical Research

Journal Of Pharmacology Pharmaceutics \& Pharmacovigilance | ISSN: 2639-5649

Journal Of Physical Medicine Rehabilitation \& Disabilities | ISSN: 2381-8670

Journal Of Plant Science Current Research | ISSN: 2639-3743

Journal Of Practical \& Professional Nursing | ISSN: 2639-5681

Journal Of Protein Research \& Bioinformatics

Journal Of Psychiatry Depression \& Anxiety | ISSN: 2573-0150

Journal Of Pulmonary Medicine \& Respiratory Research | ISSN: 2573-0177

Journal Of Reproductive Medicine Gynaecology \& Obstetrics | ISSN: 2574-2574

Journal Of Stem Cells Research Development \& Therapy | ISSN: 2381-2060

Journal Of Surgery Current Trends \& Innovations | ISSN: 2578-7284

Journal Of Toxicology Current Research | ISSN: 2639-3735

Journal Of Translational Science And Research

Journal Of Vaccines Research \& Vaccination | ISSN: 2573-0193

Journal Of Virology \& Antivirals

Sports Medicine And Injury Care Journal | ISSN: 2689-8829

Trends In Anatomy \& Physiology | ISSN: 2640-7752

Submit Your Manuscript: https://www.heraldopenaccess.us/submit-manuscript 